\title{
Data Integrity Verification
}

National Cancer Institute

\section{Source}

National Cancer Institute. Data Integrity Verification. NCI Thesaurus. Code C142477.

Authentication of information for logical dependability by a manually administered process. 